\title{
CONFERENCE IN CRETE
}

\section{Provisional scientific program set; abstracts' deadline extended}

The provisional scientific program and list of invited speakers for the MRS-sponsored International Conference on Phase Transformations in Solids, to be held in Crete June 27 July 1 , has been completed and confirms that the meeting will be as topical, timely and informative as its organizers promised. The meeting's general chairman, Thomas Tsakalakos of Rutgers University, also announced that the deadline for the submission of abstracts has been extended to March 31 , and for the submission of manuscripts until June 30 . Rutgers and the National Technical University of Crete are co-sponsors with the MRS of the meeting.

Tsakalakos said the following symposia are planned:

General Theories of Phase Transitions

A. Khachaturyan, Academy of Sciences, USSR

G. Auvert, CNET, CNS, France

Crystallography and Diffraction

Methods

N.C. Stephenson, New South Wales Institute, Australia

J.B. Cohen, Northwestern University, USA

Symmetry and Morphology

P.M. de Wolf, Technische

Hogenschool, Delft, Netherlands

J.W. Cahn, National Bureau of

Standards, USA

Statistical Mechanics and Computer

Simulations

W. Selke, Julich Institute, Germany

S. Wen, IBM, USA

Order-disorder Transformations

D. de Fontaine, University

California at Berkeley, USA

M. Fayard, ENS de Chimie de Paris,

\section{France}

Long Period Ordered Structures

D. Watanabe, Tokoku University, Japan

$R$. Comes, Universite de Paris-Sud, CNRS, France

Properties

Relationships

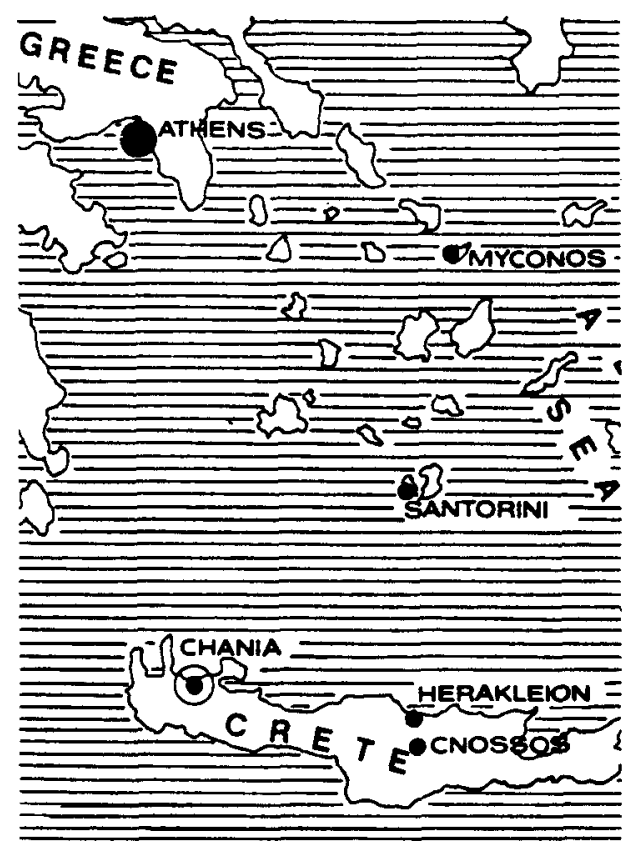

W. Morris, University of California at Berkeley, USA

J.T.M. De Hosson, Groningen, Netherlands

Diffusional Nucleation and Growth Coarsening

G. Gilmer, Bell Laboratories, USA

V. Greenhut, Rutgers University, USA

G P Zones and Clustering, Kinetics

R. Sinclair, Stanford University, USA

L.H. Schwartz, Northwestern

University, USA

Precipitation from Solid Solution

M. Hillert, Royal Institute of Technology, Sweden

R. Gronsky, Lawrence Livermore (Berkeley) Laboratories, USA

Shear Transformations - Martensitic

of Transformations

C.M. Wayman, University of Illinois, USA

P.C. Clapp, University of Connecticut, USA

Artificial Ordered Structures

J.E. Hilliard, Northwestern University, USA

R. Wilens, Bell Laboratories, USA

Microstructure Natural and Synthetic Layered

Structures
T. Tsakalakos, Rutgers University, USA

A. Freeman, Northwestern University, USA

Surface Roughening Transitions

G.H. Doehler, Max Planck Institute, Germany

J.D. Weeks, Bell Laboratories, USA

Phase Transitions of Intercalated Materials and Metal Hydrides

R. Clarke, University of Michigan, USA

G. Bambakidis, Wright State University, USA

In addition, Tsakalakos said the meeting will conclude with a panel discussion entitled "Phase Transformations A.D. 2000 - Research Targets."

A registration form is provided. Plcase complete the form and mail it to the conference chairman with the appropriate remittance. Registration fees are $\$ 100$ in advance (May 15), $\$ 115$ for late registration, and $\$ 60$ for the first 30 graduate students. Payment should be made in U.S. dollars, made payable to "MRS-Phase Transformations."

Registration fees include participation in the scientific program and admission to all sessions, a copy of the conference proceedings, abstracts of all papers, membership in the MRS, a welcoming cocktail party, the banquet and refreshments during breaks.

Accommodations for participants are available at the Crete Chandris Hotel. The room price, which includes breakfast and lunch or dinner is $\$ 21.40$ daily for a single, $\$ 34.60$ for a double, and $\$ 10$ for an extra bed in a double room. Reservations and a $\$ 50$ deposit should be sent directly to the hotel by April l. The address is Chandris Hotel, Phase Transformations, Crete, 1 Kanari Street, Piraeus, Greece.

[Continued on Page 14] 


\section{SUPERCONDUCTING MATERIALS}

Symposium speakers presented valuable reviews of relevant subjects as well as progress reports on challenging problems where structure and composition control superconducting properties. An impressive attack on the barrier problem in tunneling was mounted in the first session. Barrier perfection, or lack thereof, on an atomic scale affects the tunneling probability and the possibility of a Josephson junction technology. Various kinds of artificial barriers fabricated by magnetron and ion beam sputtering, chemical vapor and electron beam depositions, as well as naturally occurring oxide barriers were discussed.

Pollak introduced a microscopic model designed to explain the nonideal tunneling properties of niobium oxide barriers. Improved $\mathrm{SiH}_{x}$ barriers protected by $\mathrm{Si}$ for use in the SNAP process were discussed by Kroger. The excellent characteristics reported for $\mathrm{Al}_{2} \mathrm{O}_{3}$ and $\mathrm{Y}_{2} \mathrm{O}_{3}$ barriers by Gurvitch suggest they may provide reliable all$\mathrm{Nb}$ junctions. The other speakers made very useful observations on the behavior of a variety of junctions. Halbritter discussed a model in which defects in the barrier near the interface have a specially significant role.

Other review papers included a challenging one on theoretical limits to superconductivity by Varma, who demonstrated that even if lattice instabilities can be prevented, the strong coupling analysis limits $T_{c}$ to $<\sim 35 K$. Orlando discussed pairbreaking mechanisms contrasting the $\mathrm{H}_{c 2}$ behavior of $\mathrm{Nb}_{3} \mathrm{Sn}$ (already near the theoretical limits) with that of
$V_{3} G a$, and the potential role of spin polarized tunneling in developing a more quantitative understanding of this problem. DiSalvo discussed the role of lower dimensional structures which can be made by a variety of chemical and physical means.

The rich phase diagrams which can result due to the interplay of magnetic and superconducting interactions of the similar magnitude were discussed and illustrated with ternary systems by Maple.

Unusual superconducting properties were related to structure and composition in a number of systems. Ashkin showed how the high $H_{c 2}(-42$ T) for fields applied perpendicular to NbN films could be understood quantitatively, once the columnar dimensions of the films were

\section{CONFERENCE IN CRETE}

REGISTRATION FORM

International Conference on

PHASE TRANSFORMATIONS IN SOLIDS

June 27 - July 1, $1983 \quad$ Maleme-Chania, Crete, Greece
Complete the form and return it before May 15 to

Dr. Thomas Tsakalakos

Department of Mechanics and Materials Science

Rutgers University

P.O. Box 909

Piscataway, New Jersey 08854

\begin{tabular}{|c|c|c|c|}
\hline $\begin{array}{l}\text { Conference } \\
\text { Payments }\end{array}$ & $\begin{array}{l}\text { Advance Registration } \\
\text { Payment before } \\
\text { May } 15,1983 \\
\$ 100\end{array}$ & $\begin{array}{l}\text { Late Registration } \\
\text { Payment at the } \\
\text { Conference } \\
\$ 115\end{array}$ & $\begin{array}{l}\text { Graduate Student } \\
\$ 60\end{array}$ \\
\hline Please check & & & \\
\hline
\end{tabular}

NAME (Please print)

TITLE

$\triangle F F I L I A T I O N$

MAILING ADDRESS 


\section{A report on the Annual Meeting's Symposium G}

established, in terms of accepte? phenomenological theory. Tsuei postulated the presence of 100 Angstrom linear defects in amorphous films to explain the sharp peak effects due to collective pinning in amorphous $\mathrm{Nb}_{3} \mathrm{Ge}$. The bending of the flux line lattice in $V_{3} \mathrm{Si}$ single crystals as a function of field due to fluxpinning, and the existence of flux line lattice domains were reported by Christen et al.; experimentally, these results were obtained by employing sensitive neutron scattering techniques.

Durbin showed how high vacuum molecular beam epitaxy could be used to deposit single-crystal $\mathrm{Nb}$ and $\mathrm{Nb}-\mathrm{Ta}$ superlattice films for study of orientation dependence of superconducting tunneling.

Hebard showed how film morphology could be controlled from columnar to granular to amorphous by reactive ion etching with consequent changes in superconducting behavior. Batlogg discussed how unusual intrinsic properties of $\mathrm{Ba}(\mathrm{Pb}, \mathrm{Bi}) \mathrm{O}_{3}$ are related to its electronic and phonon structures.

The use of electron beam codeposition techniques in synthesizing

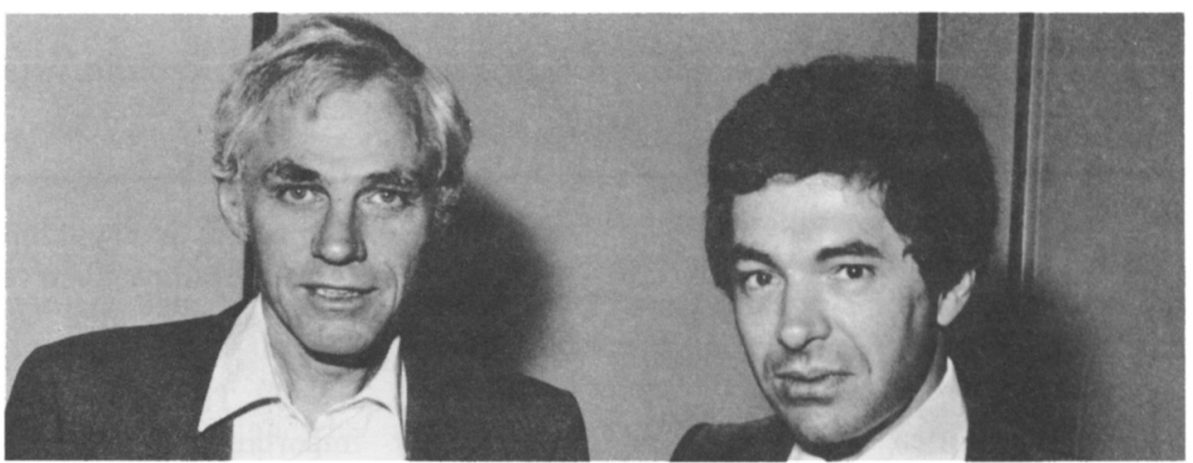

CO-CHAIRMEN T.H. Geballe of Stanford University (left) and J. Bevk of Bell Laboratories

metastable phases was reviewed by Hammond. At least four models concerning the crucial role of oxygen in stabilizing A15 structures were considered in the symposium. Braginski emphasized that composition profiling can give spurious results and presented relevant new data on metaloxide couples. Novel techniques for synthesizing metastable $\mathrm{Al} 5 \mathrm{Nb}_{3} \mathrm{Si}$ by shock compression and $\mathrm{Nb}_{3} \mathrm{Ge}$ by undercooling in a drop tube were discussed in detail by Olinger and Robinson, respectively.

The remaining papers addressed a variety of topics ranging from superconducting properties of metallic glasses to lattice instability and preparation of Chevrel phases. Particularly useful and informative was the session on intercalated superconducting materials, held jointly with the symposium on intercalated graphite. The session underscored the need for continuing interdisciplinary exchanges of ideas for wider participation of the materials science community in the field of superconducting materials.

T.H. Geballe

J. Bevk

Symposium Co-chairmen

\section{ORAL HISTORY OF MATERIALS RESEARCH}

\section{Origins of the interdisciplinary science to be investigated}

The MRS has begun the production of an oral history of materials science under the direction of Rustum Roy, past president and a member of the Education Committee.

"The rationale for this effort is that virtually all of the principal actors responsible for creating the field of materials research are still alive," Roy said. "It would be an enormous pity not to attempt to record all data relevant to the history of the growth of this subfield of science and technology."

Roy noted that materials research is scarcely a generation old, yet it occupies an unique niche in the history of science. "For three centuries as science grew it fissioned into ever smaller and more specialized disciplines," Roy said. But it became evident to some scientists in the 1950s that "some areas of solid state research demanded not a fissioning but a fusion of disciplines. 'Materials research' was born."

Roy said the MRS's initial effort will involve tape-recorded interviews with about two dozen of the scientists most intimately involved in the growth of materials science. They will be asked to concentrate on the period $1956-62$, although earlier or later events will not be excluded.

Roy said at least three copies of the tapes will be made. One will be forwarded to the AIP History of Solid State Physics project, one will be stored by Pennsylvania State University, and one will be loaned to workers in the field. In addition, the availability of the tapes will be made known in the materials science community and the history of science community. 